Check for updates

Cite this: RSC Adv., 2018, 8, 18427

Received 25th March 2018

Accepted 14th May 2018

DOI: $10.1039 / c 8 r a 02575 d$

rsc.li/rsc-advances

\section{Heteroatom tri-doped porous carbon derived from waste biomass as Pt-free counter electrode in dye- sensitized solar cells $\uparrow$}

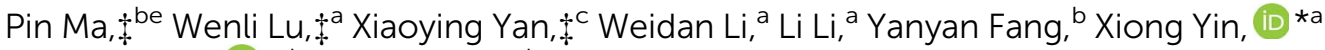 \\ Zhengang Liu (DD ${ }^{* d}$ and Yuan Lin*b
}

Strategies for environmentally friendly reutilization of waste biomass are highly desirable nowadays. Meanwhile, seeking Pt-free electrocatalysts for triiodide reduction with both high catalytic activity and low cost is critical for the development of dye-sensitized solar cells (DSCs). In the study, heteroatom tridoped porous carbons (TPCs) were prepared via carbonization of a typical food waste (fish waste) and explored as a counter electrode (CE) in a DSC. The as-prepared carbon materials possessed a porous structure with a large BET surface area of $2933 \mathrm{~m}^{2} \mathrm{~g}^{-1}$, while being simultaneously naturally doped by three heteroatoms (N, P and S). More importantly, the resultant N, P, S-tri-doped porous carbon exhibited outstanding electrochemical activity towards triiodide reduction with good stability. Moreover, the DSC with the optimized TPC electrode showed a power conversion efficiency of $7.83 \%$, which is comparable to the device with a costly Pt-based CE (8.34\%), measured under one sun illumination (AM 1.5G). This work demonstrates that carbonization of fish waste offers a cost-effective approach to prepare multifunctional carbon materials for advanced energy applications.

\section{Introduction}

Considering the growing demand of energy and worsening of environmental pollution, there is a must to develop sustainable energy systems. ${ }^{1-3}$ Dye-sensitized solar cells (DSCs) have attracted widespread attention in recent years due to their low cost, easy fabrication and relatively high power conversion efficiency. ${ }^{1-9}$ A typical DSC contains a dye-sensitized photoanode, liquid-state electrolyte containing the $\mathrm{I}_{3}{ }^{-} / \mathrm{I}^{-}$redox couple and a counter electrode $(\mathrm{CE}) .^{\mathbf{4 , 6}}$ The redox reaction at the electrolyte/CE interfaces can influence the overall efficiency of the device. Consequently, the ideal catalyst for the $\mathrm{CE}$

${ }^{a}$ State Key Laboratory of Chemical Resource Engineering, School of Science, Beijing University of Chemical Technology, Beijing 100029, P. R. China. E-mail: yinxiong@ mail.buct.edu.cn

${ }^{b}$ Beijing National Laboratory for Molecular Sciences, Key Laboratory of Photochemistry, CAS Research/Education Center for Excellence in Molecular Sciences, Institute of Chemistry, Chinese Academy of Sciences, Beijing 100190, P. R. China.E-mail: linyuan@iccas.ac.cn

${ }^{c}$ CAS Key Laboratory of Standardization and Measurement for Nanotechnology, National Center for Nanoscience and Technology, Beijing 100190, P. R. China

${ }^{d}$ Laboratory of Solid Waste Treatment and Recycling, Research Center for EcoEnvironmental Sciences, Chinese Academy of Sciences, Beijing 100085, P. R. China. E-mail: zgliu@rcees.ac.cn

${ }^{e}$ University of Chinese Academy of Sciences, Beijing 100049, P. R. China

$\dagger$ Electronic supplementary information (ESI) available: $O$ element mapping images, high resolution XPS spectra of $\mathrm{P} 2 \mathrm{p}$ and $\mathrm{S} 2 \mathrm{p}$ elements, stability test and equivalent circuits used in the study for fitting. See DOI: 10.1039/c8ra02575d \$ These authors contributed equally to this work. should possess high conductivity, good electrocatalytic activity of the redox couple, excellent stability in the corrosive electrolyte and low production costs. ${ }^{\mathbf{4 , 6}}$ In most cases, platinum metal is commonly utilized as a CE in DSCs due to its high conductivity and outstanding catalytic activity for triiodide reduction. However, its high-cost, scarcity and poor stability in corrosive $\mathrm{I}_{3}{ }^{-}$-based electrolyte limit its application in largescale manufacture. ${ }^{10-16}$ Thus, alternatives to the Pt CE have been extensively explored, such as transition metal compounds, ${ }^{14,17,18}$ conducting polymers ${ }^{19,20}$ and carbon-based materials. ${ }^{21-28}$ Among these materials, the carbon-based materials, including mesoporous carbon, ${ }^{22,27}$ hollow carbon nanospheres, ${ }^{23}$ graphene ${ }^{24-26}$ and activated carbon, ${ }^{28}$ are the most popular electrode materials owing to their intrinsic chemical inertness against corrosive electrolyte as well as high surface areas. Further investigations reveal that the edges and defect sites within the graphitic carbon framework provide active sites for efficient triiodide reduction. ${ }^{21-23,25,26}$ Moreover, the implantation of heteroatoms, such as nitrogen, sulfur and phosphorus, into the graphitic carbon lattice could induce charge redistribution, create more active sites, and thus boost the reduction of the redox couple..$^{21-23,26,29}$ For example, the lone pair electrons in both pyridinic and quaternary nitrogen states account for promoting the catalytic activity of disulfide/ thiolate redox shuttle and cobalt trisbipyridine redox mediator. ${ }^{29-31}$ With phosphorus-doping treatment on the reduced graphene oxide (rGO) CE, the power conversion efficiency of the device increased from 4.18 to $6.04 \% .^{21}$ The enhanced 
catalytic performance is ascribed to the existence of $\mathrm{P}-\mathrm{C}$ bonds distributed in the carbon matrix. ${ }^{21}$ Meanwhile, dual-doped carbonaceous materials have also been widely investigated as counter electrode materials in DSCs. ${ }^{30}$ Compared with the $\mathrm{N}$-doped (3.85\%) or S-doped (4.23\%) rGO CE-based device, the device containing $\mathrm{N}, \mathrm{S}$ dual-doped rGO $\mathrm{CE}$ showed an increased power conversion efficiency $(4.73 \%) .{ }^{30}$ The increased performance is attributed to the presence of a highly localized state of carbon within the carbon frameworks. This enormous progress indicates that carbon-based materials are promising alternative materials for Pt CE in DSCs.

Generally, the above-mentioned porous carbon materials were prepared using soft or hard template approaches with chemicals containing nitrogen and sulfur as the heteroatom sources. Additionally, the synthesis strategy involves rigorous preparation conditions and high production cost. Therefore, simply and cost-effective approaches are desirable for synthesis of porous carbon catalysts for high-efficient counter electrode. Biomass is a low-cost raw material for preparing carbon materials because of its rich organic functional groups, abundant supply and environmental friendliness. ${ }^{32-34}$ Consequently, much effort has been devoted to the preparation of functional carbon materials from renewable biomass for energy applications. For instance, pine cone flower and sea tangle were utilized to synthesize porous carbons, ${ }^{11,35}$ and soybean powder was used to prepare carbon quantum dots in photovoltaic applications. ${ }^{33}$ As reported, a large amount of fish waste is generated in the food industry daily. Fish waste is abundant in nitrogen, sulfur and phosphorous elements, besides having a high content of carbon. ${ }^{36}$ Thus, fish waste is an ideal precursor for synthesis of heteroatom-doped carbon materials. Nevertheless, to the best of our knowledge, the heteroatom doped porous carbon derived from biomass as a counter electrode in DSCs has never been investigated.

Herein, in the present study, we demonstrated the synthesis of tri-heteroatom-doped porous carbon (TPC) for DSC application via simple carbonization of fish waste. Asprepared TPC possessed a large surface area. Moreover, the TPC electrode presented both outstanding catalytic activity and high electrochemical stability on triiodide reduction. Besides, the synthesis process is simple and easy to control, and thus suitable for industrial application. These interesting results demonstrated that porous carbon derived from fish waste exhibited advantages for application as a highperformance counter electrode in DSCs.

\section{Experimental}

\subsection{Chemicals}

Potassium hydroxide, lithium perchlorate, hydrochloric acid, ethyl cellulose, terpineol and titanium isopropoxide in analytical grade were from Sinopharm Chemical Reagent Co. Ltd. Lithium iodide, iodine, dimethylpropyl imidazolium iodide, $\mathrm{H}_{2} \mathrm{PtCl}_{6}$, tert-butylpyridine and acetonitrile were purchased from Sigma-Aldrich Chemical Inc. These chemicals and solvents were in analytical grade and used as received.

\subsection{Preparation of carbon counter electrodes}

The porous carbon was prepared from fish waste according to reported processes. ${ }^{36}$ The fish scales were washed with deionized water, and then dried in an oven. The raw material was firstly pre-carbonized at $300{ }^{\circ} \mathrm{C}$ for one hour under nitrogen atmosphere. Subsequently, the pre-carbonized sample was activated with $\mathrm{KOH}$ in a quartz boat at $700{ }^{\circ} \mathrm{C}$ for 1.5 hours under nitrogen atmosphere. The as-obtained solid sample was washed with diluted $\mathrm{HCl}$ aqueous solution and de-ionized water, respectively. Finally, the product was dried at $80^{\circ} \mathrm{C}$ for $24 \mathrm{~h}$ and kept in desiccator before use.

To fabricate carbon counter electrode, the as-obtained material was firstly made to paste. ${ }^{10}$ Briefly, a certain amount of carbon powder $(0.05 \mathrm{~g}, 0.08 \mathrm{~g}$ and $0.1 \mathrm{~g})$ was grinded with $1.0 \mathrm{~mL}$ of binder solution under atmosphere and stirred for $24 \mathrm{~h}$ to get a homogeneous dispersion. The binder solution was the mixture of $0.2 \mathrm{~g}$ of ethyl cellulose and $8.0 \mathrm{~mL}$ of terpineol as well as $0.5 \mathrm{~mL}$ titanium isopropoxide. Then, the carbon pastes were coated on the FTO-glass (sheet resistance: $15 \Omega \mathrm{sq}^{-1}$, Nippon Sheet Glass Co., Japan) using doctor-blading method and dried at $120{ }^{\circ} \mathrm{C}$ for $15 \mathrm{~min}$. The electrodes were subsequently sintered under Ar atmosphere at $500{ }^{\circ} \mathrm{C}$ for $30 \mathrm{~min}$. The thickness of the porous carbon layer on the resultant electrode was estimated using SEM. For comparison, the Pt/FTO CE electrode was prepared by thermal decomposition of $\mathrm{H}_{2} \mathrm{PtCl}_{6}(5 \mathrm{mM}$ in isopropanol) on the FTO substrate using spin-coating method and sintered at $390{ }^{\circ} \mathrm{C}$ for $15 \mathrm{~min}$.

\subsection{Device assembly}

The $\mathrm{TiO}_{2}$ film consisted of a transparent $\mathrm{TiO}_{2}$ layer (particle size of 20-30 nm, thickness of $7.2 \mu \mathrm{m}$, (Ti-Nanoxide HT/SP)) and a scattering layer (a mixture of 200-400 $\mathrm{nm}$ rutile $\mathrm{TiO}_{2}$ particles, thickness of $5.8 \mu \mathrm{m}$, Dyesol (WER4-O)). ${ }^{19}$ The DSC device had a sandwich-type configuration with a N3-sensitized $\mathrm{TiO}_{2}$ electrode, a counter electrode and liquid electrolyte. The electrolyte was $0.1 \mathrm{M}$ lithium iodide, 0.05 $\mathrm{M}$ iodine, 0.6 M dimethylpropyl imidazolium iodide and $0.5 \mathrm{M}$ tert-butylpyridine in acetonitrile. The N3 photoanodes were prepared by immersing $\mathrm{TiO}_{2}$ electrode into $0.5 \mathrm{mM} \mathrm{N} 3$ dye solution for 24 hours.

\subsection{Characterization}

The morphologies and EDX mapping of the as-prepared carbon samples were observed with a field emission scanning electron microscopy (SEM, Hitachi SU-8010) and transmission electron microscopy (TEM, Hitachi HT7700). X-ray photoelectron spectroscopy (XPS) measurement was carried out with an ESCA Lab 250xi spectrometer using $\mathrm{Al} \mathrm{K} \alpha(1486.6 \mathrm{eV})$ irradiation as X-ray source. All the spectra were calibrated to the binding energy of the adventitious C 1s peak at $284.8 \mathrm{eV}$. Raman spectrum was recorded using a Renishaw inVia spectrometer. The porosity and BET surface area were obtained from nitrogen adsorption isotherms at $77 \mathrm{~K}$ using a Micromeritics 3Flex analyzer (USA). Prior to $\mathrm{N}_{2}$ sorption analysis, the sample was degassed at $300{ }^{\circ} \mathrm{C}$ for 12 hours. 
Cyclic voltammogram (CV) measurement was performed in a three-electrode cell with liquid electrolyte containing $0.1 \mathrm{M}$ $\mathrm{LiClO}_{4}, 10 \mathrm{mM} \mathrm{LiI}$, and $1 \mathrm{mM} \mathrm{I}_{2}$ in acetonitrile. The carbon electrode or Pt electrode was used as the working electrode, a saturated calomel electrode (SCE) served as the reference electrode, and platinum wire as the counter electrode. The photocurrent density-voltage $(J-V)$ of device was performed using a digital source meter (Keithley 2611, USA). A $300 \mathrm{~W}$ Xe arc lamp (Oriel) equipped with optical filters was used as a light source for simulating the solar spectrum at AM 1.5 (100 mW $\mathrm{cm}^{-2}$ ). The intensity of light was calibrated with a Si solar cell. Electrochemical impedance spectroscopy (EIS) of dummy cells was measured using a Solartron SI 1287 electrochemical interface and a Solartron 1255B frequency response analyzer in the frequency range from 0.05 to $10^{5} \mathrm{~Hz}$. EIS spectrum for DSCs with different electrodes were obtained using the same frequency response analyzer and potentiostat at amplitude of $10 \mathrm{mV}$ and the open-circuit voltage under light irradiation of $100 \mathrm{~mW} \mathrm{~cm}^{-2}$ in the frequency range from 0.05 to $10^{5} \mathrm{~Hz}$. The obtained data was fitted with a Z-View software.

\section{Results and discussion}

The morphologies of the as-obtained sample (denoted as TPC) prepared at $700{ }^{\circ} \mathrm{C}$ and the pre-carbonized fish sample were characterized with scanning electron microscopy (SEM) and transmission electron microscope (TEM). The corresponding SEM and TEM images are shown in Fig. 1. It can be clearly found that numerous pores were present in the as-obtained carbon sample, with a honeycombed morphology (Fig. 1a and b). In addition, large amount of pores formed a 3D meshy structure. Whereas, no obvious pores were observed in the case of pre-carbonized fish sample (Fig. 1c). Therefore, the 3D porous structure was formed during the carbonization process at $700{ }^{\circ} \mathrm{C}$. The formation of abundant pores was due to the activation by $\mathrm{KOH}$ and removal of hydroxyapatite. The hydroxyapatite also acted as the self-template during the pyrolysis process. Furthermore, its corresponding TEM image

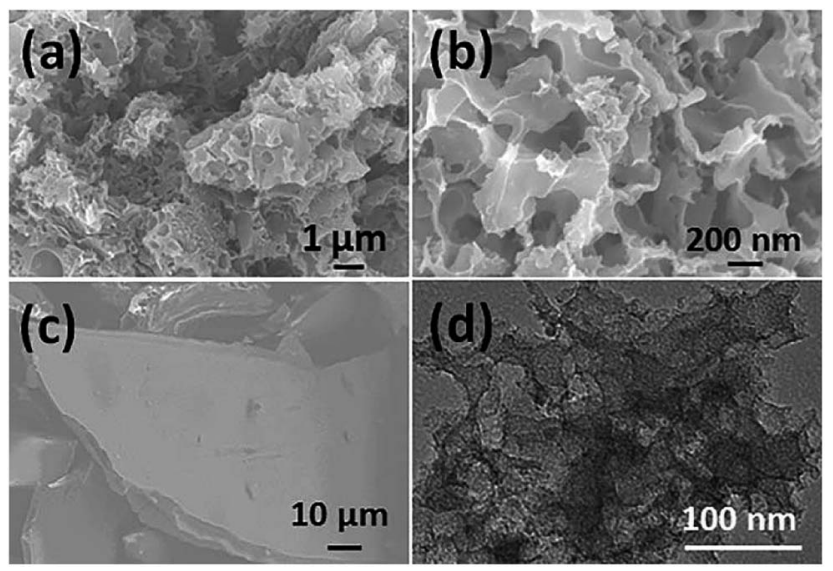

Fig. 1 SEM images of as-obtained porous carbon sample prepared at $700{ }^{\circ} \mathrm{C}$ (a and b) and fish waste pre-carbonized at $300^{\circ} \mathrm{C}$ (c); (d) typical TEM image of porous carbon sample.
(Fig. 1d) also confirms that there were abundant pores formed in the sample.

The sample was investigated using $\mathrm{N}_{2}$ physisorption measurements to provide insight into the micro- and meso-pore structures. The $\mathrm{N}_{2}$ adsorption/desorption isotherms and its corresponding pore size distribution curve of the sample are shown in Fig. 2a and b, respectively. The $\mathrm{N}_{2}$ adsorption/ desorption isotherms of the sample showed a steep increase at a low relative pressure (i.e., $P / P_{0}<0.01$ ) as a result of filling of the micropores, and a hysteresis loop was observed at a high relative pressure range (i.e., $0.6<P / P_{0}<1$ ) ascribed to the capillary condensation of $\mathrm{N}_{2}$ inside the mesopores. Its corresponding specific BET surface area and total pore volume are $2933 \mathrm{~m}^{2} \mathrm{~g}^{-1}$ and $0.81 \mathrm{~cm}^{3} \mathrm{~g}^{-1}$, respectively. The pore size distribution of TPC sample calculated using DFT method from $\mathrm{N}_{2}$ adsorption isotherm is about $2.7 \mathrm{~nm}$ (Fig. 2b). These results also confirm that hierarchical porous structure and ultrahigh surface area were simultaneously obtained for the sample via carbonization process, which are in good agreement with SEM and TEM observation. The as-obtained porous structure will promote the mass transport, and increase the number of active sites for tri-iodide reduction reaction, and thus improve the catalytic performance. ${ }^{10,27}$ Shown in Fig. 2c and $d$ are X-ray diffraction (XRD) patterns and Raman spectra of the asprepared TPC sample, respectively. Only one diffraction peak can be observed at value of $23.1^{\circ}$, assigned to the (002) plane of graphene, indicating high purity of sample without other impurities. The Raman spectra of TPC had two characteristic peaks, located at 1350 and $1590 \mathrm{~cm}^{-1}$, which are ascribed to the characteristic D and G bands of graphitic carbon materials, respectively. ${ }^{29}$ Additionally, the value for intensity ratio of $\mathrm{D}$ and
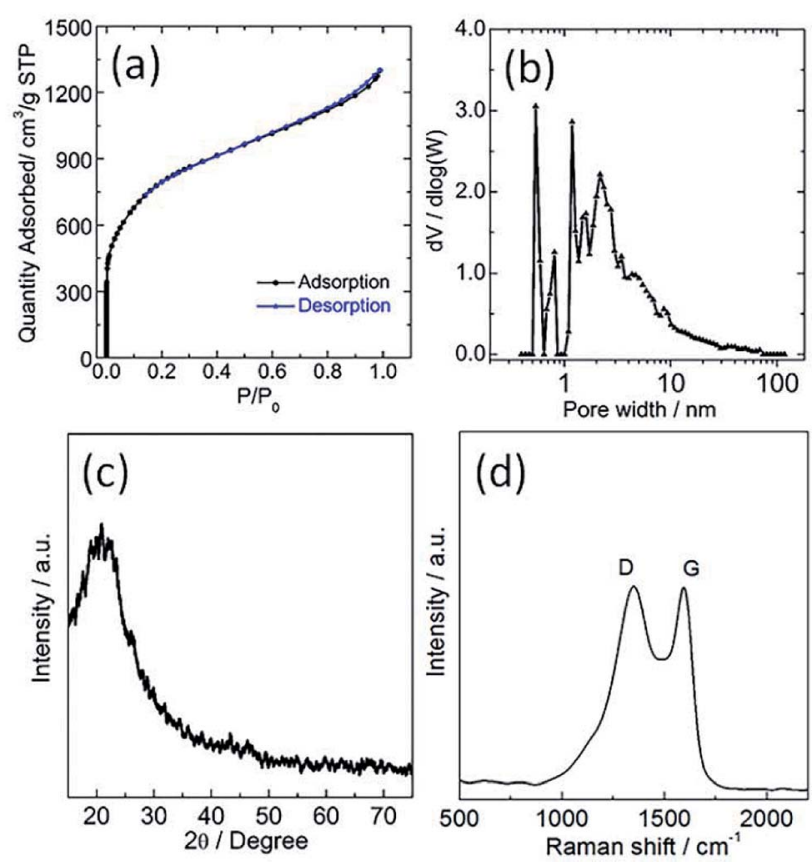

Fig. 2 (a) Nitrogen adsorption/desorption isotherms, (b) its corresponding pore size distribution (c) XRD pattern and (d) Raman spectra of as-obtained porous carbon sample. 

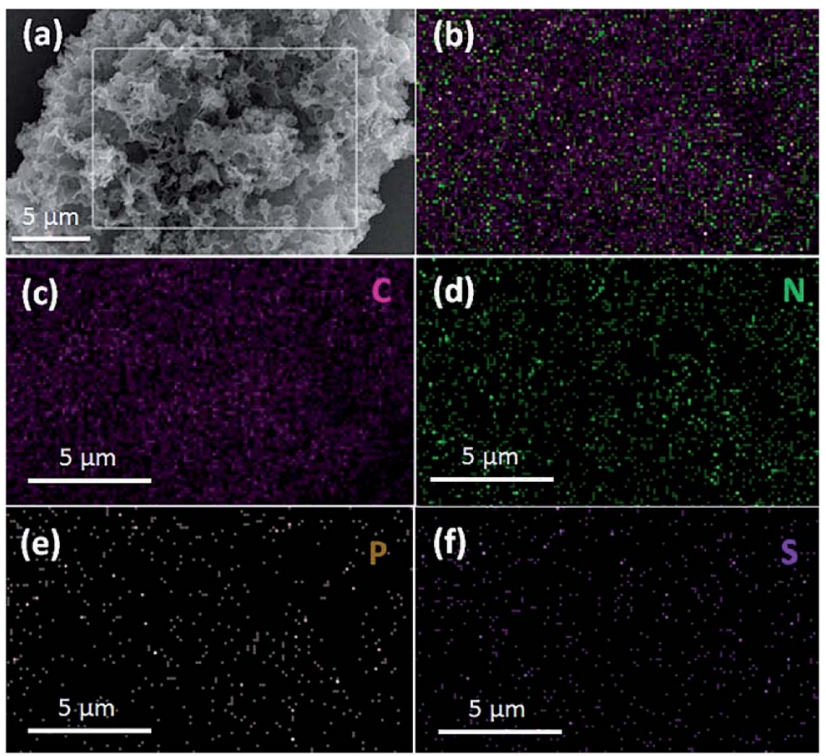

Fig. 3 SEM image (a) and typical elemental mapping image (b) for asobtained porous carbon sample with corresponding elemental mapping images of $C(c), N(d), P(e)$ and $S$ (f) elements.

G band $\left(I_{\mathrm{D}} / I_{\mathrm{G}}\right)$ is about 1.0, implying good graphitic degree of asprepared sample. ${ }^{29}$ Results from XRD and Raman indicate that the fish waste was successfully converted into graphitized carbon without other impurities via a simple pyrolysis process.

The chemical composition of the TPC material was investigated with energy-dispersive spectroscopy (EDS). The typical EDS mapping images are shown in Fig. 3. Four elements, including $\mathrm{C}, \mathrm{N}, \mathrm{P}$ and $\mathrm{S}$, were observed, with homogeneous distribution in the whole zone. Oxygen element was also present in the image, due to the exposure under the ambient atmosphere and derivation from fish scales (Fig. S1†). The TPC sample was also characterized with X-ray photoelectron spectroscopy (XPS) to understand its surface chemical states. The survey spectrum is given in Fig. S2. $\dagger$ As expected, the C, N, P and $S$ elements were detected from the surface of sample, which is in good agreement of result from elemental mapping analysis. In addition, $\mathrm{O}$ was also detected, in accordance with results of EDS characterization (Fig. S1†). The core level spectrum of C 1s is shown in Fig. 4a. It can be disintegrated into three subpeaks located at 284.6, 286.1 and $289.2 \mathrm{eV}$, respectively. The strong
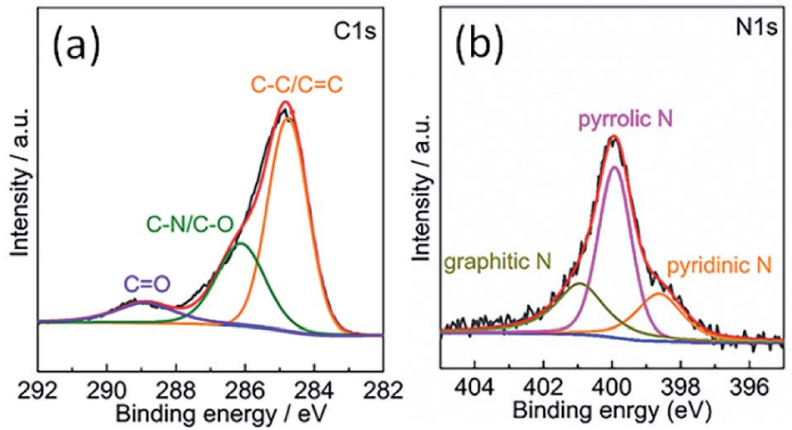

Fig. 4 XPS core level spectra of (a) C 1s and (b) N 1s of the surface of as-obtained porous carbon sample. peaks at 284.6 and $286.1 \mathrm{eV}$ are associated with the graphite-like $\mathrm{sp}^{2} \mathrm{C}$ and $\mathrm{C}$ 1s state in $\mathrm{C}-\mathrm{N} / \mathrm{C}-\mathrm{O}$, respectively. ${ }^{29,37}$ The low subpeak at $289.2 \mathrm{eV}$ is attributed to formation of $\mathrm{C}=\mathrm{O}$ bond. Meanwhile, the core level spectrum of $\mathrm{N} 1 \mathrm{~s}$ can be deconvoluted into three subpeaks at 398.6, 399.9 and $400.9 \mathrm{eV}$, as shown in Fig. 4b. The subpeaks at 398.6, 399.9 and $400.9 \mathrm{eV}$ are signals of pyridine-like, pyrrole-like and graphitic $\mathrm{N}$, respectively. ${ }^{37}$ The presence of pyridine-like and graphitic $\mathrm{N}$ are thought to promote the catalytic activity. ${ }^{26}$ Furthermore, weak signals from $\mathrm{P}$ and $\mathrm{S}$ elements were also detected. Core level spectrum of $\mathrm{P} 2 \mathrm{p}$ and S $2 p$ are shown in Fig. S2b and c, $\uparrow$ respectively. ${ }^{21,22}$ The formation of C-S-C and P-C bonds will also promote the catalytic performance. ${ }^{21,22}$ Combining the results of XPS and those from XRD and EDS characterizations, it can be confidently concluded that the N, P and S elements were successfully doped into porous carbon matrix. The estimated atomic content of $\mathrm{N}$, $\mathrm{P}$ and $\mathrm{S}$ is about 7.9, 1.2 and $1.2 \%$, respectively. Doping carbon materials with ternary heteroatoms will benefit the catalytic activity on triiodide reduction process. ${ }^{29-31}$

The catalytic activity of the as-obtained TPC carbon towards triiodide reduction was evaluated with cyclic voltammetry (CV) analysis, in comparison with that of Pt electrode. Fig. 5a shows the CV curves of TPC and Pt electrodes in the acetonitrile solution containing $\mathrm{LiClO}_{4}$ as the supporting electrolyte, with LiI and $\mathrm{I}_{2}$ as the redox couple. Two pairs of oxidation/reduction peaks were observed for Pt electrode, whereas, one typical pair of $\mathrm{I}_{3}{ }^{-}$ion oxidation/reduction peaks was present in the case of TPC carbon electrode within scanning range. During the operation of dye-sensitized solar cells, the produced $\mathrm{I}_{3}{ }^{-}$ions must be efficiently reduced to $\mathrm{I}^{-}$ions at the CE interface. ${ }^{1-6}$ Thus, the reduction peak of triiodide reduction is the research focus of $\mathrm{CV}$ analysis. ${ }^{18,20}$ The cathodic peak potential for TPC electrode is very close to that for Pt electrode. As expected, the cathodic peak current density of TPC electrode is much larger than that in Pt electrode. This is due to large surface area of TPC electrode, compared with Pt CE. These results imply that the as-prepared TPC electrode can effectively catalyze $\mathrm{I}_{3}^{-} / \mathrm{I}^{-}$redox couple, similar to the case of Pt electrode. The CV curves for two electrodes were recorded with 100 cycles to check the
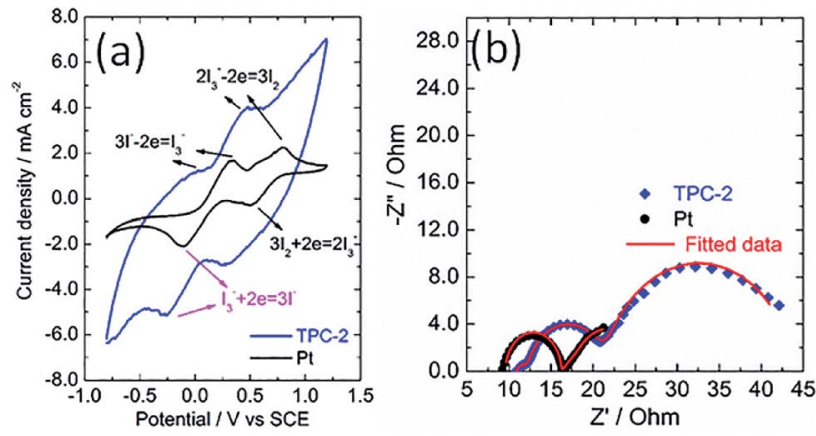

Fig. 5 (a) Cyclic voltammograms for TPC and Pt electrode at a scan rate of $100 \mathrm{mV} \mathrm{s}^{-1}$ in acetonitrile solution containing $10 \mathrm{mM}$ Lil, $1 \mathrm{mM}$ $\mathrm{I}_{2}$, and $0.1 \mathrm{M} \mathrm{LiClO}_{4}$ with a platinum wire and a SCE electrode used as counter electrode and reference electrode, respectively; (b) Nyquist plots for electrochemical impedance spectra of the symmetrical cells with two identical TPC-2 and Pt electrodes. 
electrochemical stability. The changes in cathodic and anodic current density for two electrodes are summarized in Fig. S3. $\dagger$ In the case of Pt electrode, the final cathodic and anodic current density is $73 \%$ and $59 \%$ of initial values after 100 cycles scanning. Whereas, as for TPC electrode, the final values are about $90 \%$ of initial values. The results demonstrate that TPC electrode possessed good stability in corrosive $\mathrm{I}_{3}{ }^{-}$-based electrolyte, surpassing that of Pt electrode.

The electrochemical characteristics of CE was also investigated with electrochemical impedance spectra conducting on a symmetric sandwich device configuration with two identical electrodes. ${ }^{24,25,39}$ The Nyquist plots for TPC and Pt electrodes are displayed in Fig. 5b. Two arcs were present for Pt electrode, however, three semicircles were observed in the case of TPC electrode. The presence of three semicircles is due to the porous nature of electrode materials. ${ }^{\mathbf{1 9 2 4 , 2 5}}$ The equivalent circuit for fitting experimental results is listed in Scheme S1.† The fitting data of the charge transfer resistance $\left(R_{\mathrm{ct}}\right)$ for Pt and TPC electrode are 0.42 and $0.54 \Omega \mathrm{cm}^{2}$, respectively. Obviously, the two electrodes exhibited nearly identical $R_{\mathrm{ct}}$, which is largely below than $10 \Omega \mathrm{cm}^{2}$ needed for highly-efficient dye-sensitized solar cells. ${ }^{19}$ These results indicate that TPC could be used as efficient counter electrodes for dye-sensitized solar cells.

Consequently, the TPC electrodes of different thicknesses and N3-sensitized $\mathrm{TiO}_{2}$ photoanodes were used to assemble solar cells. For comparison, the DSC containing conventional Pt $\mathrm{CE}$ was also fabricated as reference. The corresponding photocurrent density-voltage curves of devices are shown in Fig. 6a, with photovoltaic parameters summarized in Table 1. Obviously, the power conversion efficiency (PCE) of DSCs is dependent on the thickness of TPC deposited on the electrode. Initially, the PCE of device enhanced with thickness increase from 8.8 to $11.6 \mu \mathrm{m}$. However, with further enhancing the thickness to $13.2 \mu \mathrm{m}$, the efficiency of device declined to $6.91 \%$. The initial increase in photovoltaic performance with increasing thickness might be due to the increased active area for triiodide reduction, which can promote the charge transfer at the electrolyte/electrode interface. However, as thickness of carbon CE increases further, the resistance may increase and
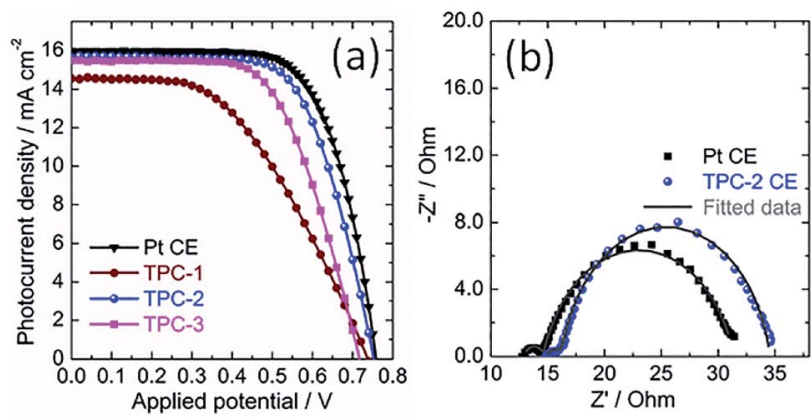

Fig. 6 (a) Characteristic photocurrent density-voltage curves of the DSCs with TPC CEs of different thicknesses and Pt CE, measured under solar simulator illumination of $100 \mathrm{~mW} \mathrm{~cm}^{-2}$ (AM 1.5G); (b) electrochemical impedance spectra of DSCs using TPC-2 and Pt CEs measured under light irradiation, at open-circuit voltage; dots present experimental results, and solid lines show fitted results.
Table 1 Photovoltaic parameters of DSCs with TPC and Pt CEs, measured under simulated solar illumination of $100 \mathrm{~mW} \mathrm{~cm}^{-2}$ (AM $1.5 \mathrm{G})$

\begin{tabular}{lllll}
\hline Counter electrode & $J_{\mathrm{sc}} / \mathrm{mA} \mathrm{cm}^{-2}$ & $V_{\mathrm{oc}} / \mathrm{V}$ & $\mathrm{FF}$ & PCE $/ \%$ \\
\hline Pt & 15.98 & 0.755 & 0.691 & 8.34 \\
TPC-1 & 14.55 & 0.735 & 0.485 & 5.19 \\
TPC-2 & 15.64 & 0.750 & 0.668 & 7.83 \\
TPC-3 & 15.46 & 0.715 & 0.625 & 6.91 \\
\hline
\end{tabular}

the diffusion of redox couple within the porous film would become more and more difficult, resulting in the decline in photovoltaic performance. As a result, among the three TPCbased solar cells, device with TPC-2 CE exhibited the highest PCE $(7.83 \%)$, with an open-circuit photovoltage $\left(V_{\text {oc }}\right)$ of $0.750 \mathrm{~V}$, a short-circuit photocurrent density $\left(J_{\mathrm{sc}}\right)$ of $15.64 \mathrm{~mA} \mathrm{~cm}^{-2}$, and fill factor (FF) of 0.668. The as-optimized photovoltaic performance for TPC-based device cloud be comparable to that for conventional Pt-based device (PCE of $8.34 \%, J_{\mathrm{sc}}$ of $15.98 \mathrm{~mA}$ $\mathrm{cm}^{-2}, V_{\text {oc }}$ of $0.755 \mathrm{~V}$ and $\mathrm{FF}$ of 0.691 ).

The photovoltaic properties of devices with different CEs were investigated using the electrochemical impedance spectra (EIS). ${ }^{19,39-42}$ EIS of DSCs with TPC-2 and Pt CEs was measured under the light illumination (100 $\mathrm{mW} \mathrm{cm}^{-2}$, AM 1.5G). The corresponding Nyquist plots are presented in Fig. 6b. Two arcs were observed in the Nyquist plots for both TPC and Pt CEbased devices. According to previous reports, the highfrequency arc is due to the charge-transfer resistance at the interface of $\mathrm{CE} /$ electrolyte $\left(R_{\mathrm{CT} 1}\right)$, and the arc at middle frequency is attributed to the charge transfer resistance at the interface of N3-sensitized $\mathrm{TiO}_{2}$ /electrolyte $\left(R_{\mathrm{CT} 2}\right)$. Meanwhile, the low frequency semicircle is ascribed to the diffusion resistance of redox couple within the electrolyte $\left(Z_{\mathrm{N}}\right)$. In most cases, the $R_{\mathrm{CT} 2}$ are commonly overlapped with $Z_{\mathrm{N}}$ due to the application of liquid state electrolyte in the study. ${ }^{19,38}$ The fitted curves with the equivalent circuit are also shown in the Fig. 6b. The fitted values of $R_{\mathrm{CT} 1}$ for TPC-2 and Pt-based devices are 1.58 and $1.52 \Omega$, respectively. The almost equal values of $R_{\mathrm{CT} 1}$ for both devices confirm that the as-prepared CE (TPC-2) could catalyze $\mathrm{I}_{3}{ }^{-} / \mathrm{I}^{-}$redox couple as efficiently as Pt CE. The corresponding values of $R_{\mathrm{CT} 2}$ are 18.21 $\Omega$ for TPC-2 CE and 16.81 $\Omega$ for Pt CE. The DSC with a TPC-2 CE showed a slightly larger $R_{\text {CT2 }}$ than that for Pt-based solar cell. The power conversion efficiency of device is dependent on the total resistance of the device. ${ }^{19,38}$ Therefore, $R_{\mathrm{CT} 1}$ and $R_{\mathrm{CT} 2}$ in the case of TPC-2 electrode can lead to a slightly low FF for TPC- 2 based devices, compared to device with a Pt CE. The high performance for device containing TPC CE could be ascribed to high surface area and well-defined porosity for promoting electrolyte diffusion within electrode, as well as heteroatom doping-induced electrocatalytic activity on $\mathrm{I}_{3}{ }^{-}$reduction.

\section{Conclusions}

Ternary heteroatom-doped porous carbons were successfully prepared via pyrolysis approach using fish waste as raw material 
in an inert atmosphere. The $\mathrm{N}, \mathrm{P}$ and $\mathrm{S}$ elements contained in the fish waste were doped simultaneously into porous carbon matrix during the pyrolysis process. The resultant porous carbons possessed both large surface area and highly graphitized nanostructures, and thus presented perfect catalytic activity on triiodide reduction. The optimized DSC with a TPC-2 CE exhibited a power conversion efficiency of $7.83 \%$, which is comparable to that for the device with a Pt CE $(8.34 \%)$. The results indicate that porous carbon derived from fish waste could catalyze as efficiently as noble metal Pt on the triiodide reduction in DSC. The idea of "making waste profitable" reported here could be suitable for exploring low-cost non-noble metal catalysts in a wide variety of applications.

\section{Conflicts of interest}

There are no conflicts to declare.

\section{Acknowledgements}

This work was financially supported by the National Natural Science Foundation of China (Grant No. 21771019, 51673204). $\mathrm{X}$. Yin would like to acknowledge the support from the Fundamental Research Funds for the Central Universities (buctrc201706), the Key Laboratory of Applied Surface and Colloid Chemistry, Ministry of Education (Shaanxi Normal University) (2017028). Z. Liu thanks to financial support from the "100 Talents" Program of the Chinese Academy of Sciences (No. Y5N41I1C01).

\section{Notes and references}

1 F. Bella, C. Gerbaldi, C. Barolo and M. Grätzel, Chem. Soc. Rev., 2015, 44, 3431-3473.

2 A. Hagfeldt, G. Boschloo, L. Sun, L. Kloo and H. Pettersson, Chem. Rev., 2010, 110, 6595-6663.

3 S. Mozaffari, M. R. Nateghi and M. B. Zarandi, Renewable Sustainable Energy Rev., 2017, 71, 675-686.

4 J. Wu, Z. Lan, J. Lin, M. Huang, Y. Huang, L. Fan, G. Luo, Y. Lin, Y. Xie and Y. Wei, Chem. Soc. Rev., 2017, 46, 59756023.

5 J. Wu, Z. Lan, J. Lin, M. Huang, Y. Huang, L. Fan and G. Luo, Chem. Rev., 2015, 115, 2136-2173.

6 Z. Jin, M. Zhang, M. Wang, C. Feng and Z.-S. Wang, Acc. Chem. Res., 2017, 50, 895-904.

7 W.-Q. Wu, H. Feng, H. Chen, D. Kuang and C. Su, J. Mater. Chem. A, 2017, 5, 12699-12717.

8 W.-Q. Wu, D. Chen, R. A. Caruso and Y.-B. Cheng, J. Mater. Chem. A, 2017, 5, 10092-10109.

9 W.-Q. Wu, D. Chen, Y.-B. Cheng and R. A. Caruso, Sustainable Energy Fuels, 2017, 1, 1960-1967.

10 G. Wang, S. Kuang, D. Wang and S. Zhuo, Electrochim. Acta, 2013, 113, 346-353.

11 L. Wang, Y. Shi, X. Bai, Y. Xing, H. Zhang, L. Wang, W. Guo, N. Wang, T. Ma and M. Grätzel, Energy Environ. Sci., 2014, 7, 343-346.
12 L. Wang, Z. Gao, J. Chang, X. Liu, D. Wu, F. Xu, Y. Guo and K. Jiang, ACS Appl. Mater. Interfaces, 2015, 7, 20234-20244.

13 X. Meng, C. Yu, X. Song, Z. Liu, B. Lu, C. Hao and J. Qiu, J. Mater. Chem. A, 2017, 5, 2280-2287.

14 S. Chen, A. Xu, J. Tao, H. Tao, Y. Shen, L. Zhu, J. Jiang, T. Wang and L. Pan, ACS Sustainable Chem. Eng., 2015, 3, 2652-2659.

15 A. G. Kannan, J. Zhao, S. G. Jo, Y. S. Kang and D.-W. Kim, J. Mater. Chem. A, 2014, 2, 12232-12239.

16 Y.-A. Leu, M.-H. Yeh, L.-Y. Lin, T.-J. Li, L.-Y. Chang, S.-Y. Shen, Y.-S. Li, G.-L. Chen, W.-H. Chiang, J.-J. Lin and K.-C. Ho, ACS Sustainable Chem. Eng., 2017, 5, 537-546.

17 Q. Tang, H. Zhang, Y. Meng, B. He and L. Yu, Angew. Chem., Int. Ed., 2015, 54, 11448-11452.

18 F. Dong, Y. Guo, P. Xu, X. Yin, Y. Li and M. He, Sci. China Mater., 2017, 60, 295-303.

19 X. Yin, F. Wu, N. Fu, J. Han, D. Chen, P. Xu, M. He and Y. Lin, ACS Appl. Mater. Interfaces, 2013, 5, 8423-8429.

20 W. Liu, Y. Fang, P. Xu, Y. Lin, X. Yin, G. Tang and M. He, ACS Appl. Mater. Interfaces, 2014, 6, 16249-16256.

21 Z. Wang, P. Li, Y. Chen, J. He, J. Liu, W. Zhang and Y. Li, J. Power Sources, 2014, 263, 246-251.

22 W. Yang, X. Ma, X. Xu, Y. Li, S. I. Raj, G. Ning, A. Wang and S. Chen, J. Power Sources, 2015, 282, 228-234.

23 D.-S. Yang, C. Kim, M. Y. Song, H.-Y. Park, J. C. Kim, J.-J. Lee, M. J. Ju and J.-S. Yu, J. Phys. Chem. C, 2014, 118, 1669416702.

24 L. Kavan, J.-H. Yum, M. K. Nazeeruddin and M. Grätzel, ACS Nano, 2011, 5, 9171-9178.

25 L. Kavan, J.-H. Yum and M. Grätzel, Nano Lett., 2011, 11, 5501-5506.

26 S. Hou, X. Cai, H. Wu, X. Yu, M. Peng, K. Yan and D. Zou, Energy Environ. Sci., 2013, 6, 3356.

27 G. Wang, W. Xing and S. Zhuo, J. Power Sources, 2009, 194, 568-573.

28 K. Li, Y. Luo, Z. Yu, M. Deng, D. Li and Q. Meng, Electrochem. Commun., 2009, 11, 1346-1349.

29 Y. Xue, J. Liu, H. Chen, R. Wang, D. Li, J. Qu and L. Dai, Angew. Chem., Int. Ed., 2012, 51, 12124-12127.

30 Q. Luo, F. Hao, S. Wang, H. Shen, L. Zhao, J. Li, M. Grätzel and H. Lin, J. Phys. Chem. C, 2014, 118, 17010-17018.

31 L. Song, Q. Luo, F. Zhao, Y. Li, H. Lin, L. Qu and Z. Zhang, Phys. Chem. Chem. Phys., 2014, 16, 21820-21826.

32 W. Qian, F. Sun, Y. Xu, L. Qiu, C. Liu, S. Wang and F. Yan, Energy Environ. Sci., 2014, 7, 379-386.

33 Y. Meng, Y. Zhang, W. Sun, M. Wang, B. He, H. Chen and Q. Tang, Electrochim. Acta, 2017, 257, 259-266.

34 G. Xu, J. Han, B. Ding, P. Nie, J. Pan, H. Dou, H. Li and X. Zhang, Green Chem., 2015, 17, 1668-1674.

35 G. Nagaraju, J. H. Lim, S. M. Cha and J. S. Yu, J. Alloys Compd., 2017, 693, 1297-1304.

36 Z. Liu, F. Zhang, T. Liu, N. Peng and C. Gai, J. Environ. Manage., 2016, 182, 446-454.

37 X. Gong, Z. Li, Q. Hu, R. Zhou, S. Shuang and C. Dong, ACS Appl. Mater. Interfaces, 2017, 9, 38761-38772.

38 X. Yin, Z. Xue and B. Liu, J. Power Sources, 2011, 196, 24222426. 
39 X. Yin, Y. Guo, Z. Xue, P. Xu, M. He and B. Liu, Nano Res., 2015, 8, 1997-2003.

40 X. Yin, Z. Xu, Y. Guo, P. Xu and M. He, ACS Appl. Mater. Interfaces, 2016, 8, 29580-29587.
41 Z. Xu, X. Yin, Y. Guo, Y. Pu and M. He, J. Mater. Chem. C, 2018, 6, 4746-4752.

42 Y. Wang, Y. Guo, W. Chen, Q. Luo, W. Lu, P. Xu, D. Chen, X. Yin and M. He, Appl. Surf. Sci., 2018, 452, 232-238. 